\title{
Role of sleep duration and sleep-related problems in the metabolic syndrome among children and adolescents
}

\author{
Leonardo Pulido-Arjona', Jorge Enrique Correa-Bautista', Cesar Agostinis-Sobrinho², Jorge Mota², Rute Santos ${ }^{3}$,
} María Correa-Rodríguez ${ }^{4}$, Antonio Garcia-Hermoso ${ }^{5}$ and Robinson Ramírez-Vélez ${ }^{1 *}$

\begin{abstract}
Background: There is increasing recognition that sleep is a risk factor for metabolic syndrome (MetS). The aim of the present study was to analyze the relationship between self-reported sleep duration, sleep-related problems and the presence of MetS in children and adolescents from Bogotá, D.C., Colombia.

Methods: This is a cross-sectional analysis from the FUPRECOL study (2014-15). Participants included 2779 (54.2\% girls) youth from Bogota (Colombia). MetS was defined as the presence of $\geq 3$ of the metabolic abnormalities (hyperglycemia, hypertriglyceridemia, low high-density lipoprotein cholesterol [HDL-c], hypertension, and increased waist circumference) according to the criteria of de Ferranti/Magge and colleges. Self-reported sleep duration and sleep-related problems were assessed with the BEARS questionnaire.

Results: Logistic regression analysis showed that boys who meet recommended duration of sleep had a decreased risk of elevated blood glucose levels (Odds Ratio [OR] $=0.71,95 \% \mathrm{Cl}[0.40-0.94] ; p=0.031$ ) compared to boys who have short-long sleep duration. Also, compared to young without sleep problems, excessive sleepiness during the day was related to low HDL-c levels in boys $(\mathrm{OR}=1.36,95 \% \mathrm{Cl}[1.02-1.83] ; p=0.036)$ and high triglyceride levels in girls $(\mathrm{OR}=1.28,95 \% \mathrm{Cl}[1.01-1.63] ; p=0.045)$. Girls with irregular sleep patterns had decreased HDL-c levels $(\mathrm{OR}=0$. 71, 95\%Cl [0.55-0.91]; $p=0.009)$.

Conclusions: Recommended sleep duration was associated with a decreased risk of elevated fasting glucose levels in boys, and sleep problems was related to lower HDL-c in girls and higher triglyceride levels in boys. These findings suggested the clinical importance of improving sleep hygiene to reduce metabolic risk factors in children and adolescents.
\end{abstract}

Keywords: Sleep quality, Cardiometabolic risk, Childhood obesity

\section{Background}

Insufficient sleep has been postulated as predictors of emerging cardiometabolic risk markers [1]. Sleep duration and sleep quality have been associated with obesity [2], diabetes [3], and hypertension [4], strong and independent indicators of cardiovascular disease risk.

Sleep duration has recently been recognized as a risk factor for metabolic syndrome (MetS) [5]. To date, most studies examining the relationships between sleep

\footnotetext{
*Correspondence: robin640@hotmail.com; robinson.ramirez@urosario.edu.co ${ }^{1}$ Center of Studies in Physical Activity Measurements, School of Medicine and Health Sciences, Universidad del Rosario, Bogotá D.C, Colombia

Full list of author information is available at the end of the article
}

duration and MetS or its components (waist circumference percentile, triglyceridemia, HDL-c, blood pressure, and fasting glucose) have been conducted in adults, and little is known about these relationships in the pediatric population. In addition, the limited research has yielded inconsistent findings [6-13]. Evidence for an association with sleep duration appears more consistent for fasting glucose, suggesting that both short and long sleep duration might play a determinant role MetS in children and youth $[7,9]$.

Similarly, only few studies have investigating the relationships between sleep-related problems and MetS, as most research has focused on sleep duration [14, 15]. 
For example, Kuula et al. (2016) reported that poor sleep duration during the transition to early adolescence was related to an atherogenic lipid profile, and with this effect is less prominent in boys [14]. Likewise, long sleeper during the day was associated with low high-density lipoprotein cholesterol (HDL-c) in girls (but not in boys) in a large sample of children aged 11-12 years from The Netherlands [15]. Regarding sleep quality, poor sleep has also been associated with high diastolic blood pressure and waist circumference (but not with other MetS components) in a cohort of 135 Brazilian children and adolescents [16]. Therefore, because previous research reported inconsistent results and considering that the sample sizes of these studies were relatively small, no conclusion can be drawn as yet.

Identifying the impact of sleep duration and sleeprelated problems on metabolic risk factors in children and adolescents will enable the establishment of early interventions for pediatric sleep problems. Due to the absence of sufficient conclusive evidence regarding the effect of sleep characteristics on metabolic risk factors in pediatric populations, the aim of the present study was to analyze the relationship between self-reported sleep duration, sleep-related problems and the presence of MetS in children and adolescents from Bogotá, D.C., Colombia.

\section{Methods}

\section{Study design and participants}

During the 2014-2015 school years (academic year), we examined a cross-sectional component of the FUPRECOL study [17] (in spanish: Asociación de la fuerza prensil con manifestaciones de riesgo cardiovascular tempranas en niños $y$ adolescentes colombianos). The sample consisted of children and adolescents $(n=4000$ boys and $n=4000$ girls) aged 9-17.9 years. Blood sampling was randomly performed in one third of the recruited subjects $(n=2900)$. In this subgroup, valid data were available for 2779 apparently healthy children and adolescents without any physical or mental medical condition diagnosis (54.2\% girls) on self-reported hours of sleep and all components included in the biochemical samples. Participants belong to low and middle socioeconomic status (1-3 defined by the Colombian government). Children and adolescents were enrolled in public elementary and high schools (grades 5 through 11) from the capital district of Bogotá in a municipality in the Cundinamarca Department in the Andean region. A convenience sample of volunteers was included and grouped by sex and age in 1-year increments (a total of nine groups).

\section{Anthropometric measurements}

Participants were instructed to wear shorts and a t-shirt for the physical examination. They were also required to remove all jewelry and other metal objects. Once the subjects were barefoot and in their underwear, their body weight $(\mathrm{kg})$ was measured using an electric scale (Model Tanita ${ }^{\circ}$ BC- $418^{\circ}$ Tokyo, Japan) with a range of $0-200 \mathrm{~kg}$ and accurate to within $100 \mathrm{~g}$. Height was measured with a portable stadiometer with a precision of $0.1 \mathrm{~mm}$ and a range of 0-2.50 $\mathrm{m}$ (Seca ${ }^{\circ} 206$, Hamburg, Germany). Body mass index (BMI) was calculated as weight $(\mathrm{kg}) /$ height $\left(\mathrm{m}^{2}\right)$, and BMI-z score was calculated using the World Health Organization Growth Reference 2007 [18]. The waist circumference (WC) $(\mathrm{cm})$ was measured as the narrowest point between the lower costal border and the iliac crest. When this point was not evident, it was measured at the midpoint between the last rib and the iliac crest, using a metal tape measure (Lufkin W606 $\mathrm{PM}^{\circ}$, Parsippany, New Jersey, USA), in accordance with the International Society for the Advancement of Kinanthropometry guidelines [19]. The evaluation process was carried out by a team of professionals (four physical activity Master's degree students and physiotherapist professors) with extensive experience in anthropometric measurement. Two percent of the sample was measured twice in order to ensure measurement consistency. The technical error of measurement was less than $2 \%$ for all anthropometric variables [17].

\section{Blood pressure}

Systolic (SBP) and diastolic blood pressure (DBP) was taken on the left arm at the heart level with an automatic device (Riester Ri-Champion model, Jungingen, Germany) while the participants were sitting still. The blood pressure monitor cuff was placed two to three finger-widths above the bend of the arm, and a 2-min pause was allowed between the first and second measurements taken with a standard cuff for an arm circumference of $17-22 \mathrm{~cm}$.

\section{Blood sampling and analysis}

After the subjects had fasted for 10-12 h, blood samples were obtained by capillary sampling between 6:00 a.m. and 8:00 a.m. Participants were asked not to engage in prolonged exercise in the $24 \mathrm{~h}$ prior to testing. The biochemical profile included the following: (i) HDL-c, (ii) triglycerides, (iii) total cholesterol, and (iv) fasting blood glucose, assayed by enzymatic colorimetric methods. The inter-assay reproducibility (coefficient of variation) was determined from 16 replicate analyses of eight plasma pools over a period of 15 days. The percentages obtained were $2.6 \%$ for triglycerides, $2.0 \%$ for total cholesterol, $3.2 \%$ for HDL-c, $3.6 \%$, and $1.5 \%$ for fasting glucose. 


\section{Metabolic syndrome diagnosis}

MetS was defined in accordance with the updated harmonized criteria of de Ferranti et al. [20] and Magge et al. [21] based on age/gender/height criteria. Participants were considered to have MetS if they showed three or more of the following: (1) abdominal obesity (WC $>75$ th percentile), (2) hypertriglyceridemia ( $\geq 100 \mathrm{~g} / \mathrm{dL})$, (3) low HDL-c $(<50 \mathrm{mg} / \mathrm{dL})$, (4) high blood pressure ( $>90$ th percentile), and (5) high fasting glucose ( $\geq 110 \mathrm{mg} / \mathrm{dL})$.

\section{Cardiorespiratory fitness assessment}

Cardiorespiratory fitness was measured using the 20-m shuttle run test as previously described by Léger [22]. Results were recorded to the nearest stage completed. The Léger equation was used to determine $\mathrm{VO}_{2}$ peak $\left(\mathrm{ml} \cdot \mathrm{kg} \cdot \mathrm{min}^{-1}\right)$ in each participant. The test was performed in according to the standardized protocol and the detailed description of this test can be found elsewhere [23]. The reproducibility ( $R$ ) of our data was $R=0.84$. Intra-rater reliability was assessed by determining the intra-class correlation coefficient (ICC $=0.96$, CI 95\% 0.95-0.97). We used this parameter as covariate due to its relationship with sleep quality [24].

\section{Sexual maturity}

Participants self-assessed their pubertal stage of secondary sex characteristics (breast and pubic hair development for girls, genital and pubic hair development for boys; ranging from stage I to V), according to the criteria of Tanner and Whitehouse [25].

\section{Self-reported duration and sleep problems}

Participants self-reported their sleep duration as the average nightly sleep time on weekdays and weekend days by answering the following questions: How long do you generally sleep on school days? How long do you generally sleep on the weekend? According to the recommendations of the National Sleep Foundation [26] sufficient sleep was considered young who slept between 9 to $11 \mathrm{~h}$ or 8 to 10 in children and adolescents, respectively. Short and long sleep duration were defined according to current recommendation as 8 to $9 \mathrm{~h}$, and 10 to $11 \mathrm{~h}$ sleep per night, respectively [26].

Additionally, we used the BEARS questionnaire to recognize sleep-related problems (sleep quality) [27]. This screening tool prompts the professional care to ask scholar children an initial screening question about possible problems in each domain, eliciting a yes or no response. This instrument includes a set of basic questions that evaluate sleep-related areas such as (i) bedtime problems, including difficulty going to bed and falling asleep; (ii) excessive daytime sleepiness, which includes behaviors typically associated with daytime somnolence in children; (iii) awakenings during the night; (iv) regularity and duration of sleep; (v) and snoring. Because sleep-related problems were self-reported, and subjects are usually not aware of snoring, this item was not assessed. The responses were restricted to the last 7 days, and the frequency option was categorized as 'yes' or 'no'. This questionnaire has shown adequate validity and reliability in young populations $[27,28]$. On the website of the Spanish Association of Primary Care Pediatrics, it is provided the Spanish translation of BEARS that was used in this study (http://www.aepap.org/gtsiaepap/). Recently, Bastida-Pozuelo et al. [28] analysed the validity of the BEARS questionnaire evaluating how well it performs to distinguish young populations with specific sleep problems using the Children Sleep Habits Questionnaire scores as the gold standard. These authors shown the participants aged 2-16 years who, according to the BEARS, had a sleep problem obtained scores on the Sleep Habits Questionnaire scores-related subscales significantly higher than children and adolescents who did not have a sleep problem (all Ps $<0.05$ ). Nevertheless, considering the lack of psychometric properties in the Colombian population, a reliability analysis was conducted, revealing internal consistency results (Cronbach's alpha) of 0.75 ( $\mathrm{min} 0.70$ to max 0.76). Furthermore, in a sub-sample of 229 schoolaged children (mean age $12.8 \pm 2.4$ years, weight $46.2 \pm 12.4 \mathrm{~kg}$, height $1.50 \pm 0.1 \mathrm{~m}$, and BMI $19.9 \pm 3.1 \mathrm{~kg} / \mathrm{m}^{2}$ ) and a 7-day period between each test, test-retest (Kappa index) reproducibility values of 0.665 were obtained for the four questions of the BEARS questionnaire.

The surveys were administered to school-aged children in groups of 20-50 participants in classrooms in order to maintain privacy and to give the students free choice to participate and in the presence of at least two qualified researchers. The questionnaires were completed in approximately $3-5 \mathrm{~min}$. Prior to questionnaire administration, the necessary guidelines were provided for their completion, highlighting the need to carefully read the items and the importance of sincerity and confidentiality when answering them.

\section{Ethics statement}

The FRUPECOL study was conducted in accordance with the Helsinki Declaration for Human Studies and approved by the Colombian Data Protection Authority (Resolution 008430/1993 Ministry of Health) and the Review Committee for Research on Human Subjects at the University of Rosario (Code $\mathrm{N}^{\circ}$ CEIABN026-000262). All participants were informed of the study's goals, and written informed consent was obtained from participants and their parents or legal guardians. 


\section{Statistical analysis}

The continuous variables were expressed as mean (SD), and the categorical variables were expressed as frequencies. To assess statistical normality, the KolmogorovSmirnov test was used. Because of their skewed distribution, the following variables were log-transformed before analysis: WC, HDL-c, fasting glucose, triglycerides, SBP and DBP. To aid interpretation, data were backtransformed from the log scale for presentation in the results.

Differences between the sexes were analyzed by Student's $t$-test or chi-square test. ANCOVA analysis was used to evaluate differences in sleep duration and sleep problems categories for each MetS components. We performed logistic regression order to determine the risk of having MetS or the altered levels of each of the MetS components taking as reference group participants who slept short-long duration or have sleep problems, respectively. Results were expressed as odds ratios (ORs) and $95 \%$ CI. Analyses were adjusted by age, sexual maturity, body mass index (except for waist circumference), and cardiorespiratory fitness. SPSS version 22.0 (SPSS Inc., Chicago, IL) software was used for statistical analyses. A $p$ value 0.05 denoted statistical significance.

\section{Results}

Table 1 shows the characteristics of the participants, by sex. The mean age of the sample was 13.21 (2.2) years. Boys were heavier and taller and had better cardiorespiratory fitness than girls. In contrast, girls had higher BMI values, higher triglyceride levels, and a longer average sleep duration at the weekend than boys. The average sleep duration over the entire week was 8.11 (1.61) hours per night. The prevalence of the MetS was 9.65\% and was statistically significantly higher in girls than in boys $(p<0.05)$.

Table 2 shows the metabolic parameters according to sleep duration and sleep-related problems. In boys, diastolic blood pressure values were significantly higher in those without bedtime problems, and triglyceride values were significantly higher in those with excessive daytime sleepiness. In girls, systolic blood pressure was significantly higher in the absence of bedtime problems.

Logistic regression analysis of sleep time, sleep-related problems, and the MetS components are shown in Table 3. Boys who slept recommended duration were at a decreased risk of higher fasting blood glucose $(\mathrm{OR}=0.71,95 \% \mathrm{CI}[0.40-0.94], p=0.031)$ compared to those who reported short-long duration. Also compared to young without sleep problems, those who reported excessive daytime sleepiness had lower HDL-c levels $(\mathrm{OR}=1.36,95 \%$ CI [1.02-1.83], $p=0.036)$. In girls, excessive daytime sleepiness also was associated with an increased risk of elevated triglyceride levels $(\mathrm{OR}=1.28$,
95\%CI [1.01-1.63], $p=0.045)$, while an irregular sleep pattern was related to low HDL-c levels $(\mathrm{OR}=0.71$, $95 \%$ CI [0.55-0.91], $p=0.009)$.

\section{Discussion}

Sleep duration and sleep patterns have been proposed as potential risk factors contributing to increased metabolic risk at an early age [29]. This study investigated the relationships between sleep time and sleep-related problems and metabolic risk factors in a cohort of 2779 children and adolescents, suggesting a determinant role of sleep in components of MetS. To our knowledge, our study comprised the largest cohort of Latin American children assessed to date.

In recent years, there has been an increasing number of studies about sleep duration and its impact on metabolic health during childhood and adolescence $[1,5]$. With regard to glucose and insulin homeostasis, accumulating evidence suggests that sleep time may play a relevant role [30]. However, most published studies examining the association between sleep duration and glycaemia have been conducted in adults, and the limited data available in children and adolescents has demonstrated contradictory findings [6-9]. In this regard, a recent systematic review in young people (aged 019 years) suggested that insufficient sleep duration might has a negative effect on glucose homeostasis [31]. In the present study and confirming above-mentioned results, we identified that recommended duration was associated with decreased levels of fasting glucose in boys. Sleep duration was also recently positively associated with insulin resistance in a cohort of obese children and adolescents [32], suggesting that children 10-13 years old who slept $<9$ h per day were more likely to have higher insulin and HOMA-IR levels and lower HDL-c levels compared with subjects who slept 9-10 h/ per day and > $10 \mathrm{~h}$ per day. Interestingly, previous published studies in young population found U-shaped relationships between total sleep time and glucose levels [7, 9]. Thus, in the Cleveland Children's Sleep and Health Cohort Study, adolescents (aged 16-19 years) who slept $7.75 \mathrm{~h}$ per night had a lower risk of elevated fasting blood glucose and those with short sleep duration $(5.0 \mathrm{~h})$ or long sleep duration $(10.5 \mathrm{~h})$ had HOMA levels that were about $25 \%$ [9]. The lack of relationship between shorter sleep duration and glucose levels reported in our study may be explained by the different confounding variables included in the analysis and the data on sleep reported as the mean of the days. In this context, experimental studies have identified that sleep restriction and extension exert an effect on insulin sensitivity, but the underlying mechanistic links have not been well determined [33, 34]. Based on our results and previous research, we may speculate that excessive amounts of sleep contribute to 
Table 1 Characteristics of the sample, by sex

\begin{tabular}{|c|c|c|c|}
\hline Characteristics & $\begin{array}{l}\text { Boys } \\
(n=1272)\end{array}$ & $\begin{array}{l}\text { Girls } \\
(n=1507)\end{array}$ & $P$ value \\
\hline \multicolumn{4}{|l|}{ Anthropometrics } \\
\hline Age, (years) & $13.26(2.19)$ & $13.17(2.21)$ & 0.294 \\
\hline Weight, (kg) & $47.55(12.55)$ & $46.16(10.67)$ & 0.002 \\
\hline Height, $(\mathrm{cm})$ & $155.55(13.87)$ & $150.64(9.54)$ & $<0.001$ \\
\hline Body mass index, $\left(\mathrm{kg} / \mathrm{m}^{2}\right)$ & $19.33(2.90)$ & $20.11(3.18)$ & $<0.001$ \\
\hline Body mass index, (z-score) & $0.39(0.91)$ & $0.43(0.78)$ & $<0.001$ \\
\hline Waist circumference, $(\mathrm{cm})$ & $65.69(7.42)$ & $63.70(7.42)$ & $<0.001$ \\
\hline \multicolumn{4}{|l|}{ Sexual maturity } \\
\hline Prepuberty, n (\%) & $85(6.68)$ & $78(5.17)$ & \\
\hline Puberty, n (\%) & $650(51.11)$ & $734(48.77)$ & 0.157 \\
\hline Postpuberty, n (\%) & $537(42.21)$ & $696(46.18)$ & \\
\hline \multicolumn{4}{|l|}{ Blood sampling } \\
\hline $\mathrm{HDL}-\mathrm{c}_{1}(\mathrm{mg} / \mathrm{dL})$ & $46.91(12.36)$ & $47.49(12.23)$ & 0.215 \\
\hline Triglycerides, (mg/dL) & $85.19(39.07)$ & $96.53(54.73)$ & $<0.001$ \\
\hline Fasting blood glucose, (mg/dL) & $83.45(15.82)$ & $81.52(15.72)$ & 0.001 \\
\hline Systolic blood pressure, $(\mathrm{mmHg})$ & $113.39(14.04)$ & $110.30(12.36)$ & $<0.001$ \\
\hline Diastolic blood pressure, $(\mathrm{mmHg})$ & $68.19(9.31)$ & $68.45(8.59)$ & 0.443 \\
\hline Cardiorespiratory fitness, $\left(\mathrm{ml}^{\prime} \mathrm{kg} \cdot \mathrm{min}^{-1}\right)$ & $50.13(3.66)$ & $35.55(2.79)$ & $<0.001$ \\
\hline \multicolumn{4}{|l|}{ Sleep duration } \\
\hline Week days, hours/night & $8.11(1.61)$ & $8.09(1.69)$ & 0.811 \\
\hline Weekend, hours/night & $9.63(1.85)$ & $9.82(1.91)$ & 0.010 \\
\hline Short-long duration ${ }^{a}$ & $479(37.7)$ & $939(62.3)$ & 0.102 \\
\hline \multicolumn{4}{|l|}{ Sleep patterns } \\
\hline Short sleep duration, $n(\%)$ & $900(70.48)$ & $1055(69.78)$ & 0.686 \\
\hline Bedtime problems, $\mathrm{n}(\%)$ & $292(22.87)$ & $374(24.74)$ & 0.249 \\
\hline Excessive day sleepiness, n (\%) & $396(31.01)$ & $673(44.51)$ & $<0.001$ \\
\hline Awakenings during the night, $\mathrm{n}(\%)$ & $248(19.42)$ & $320(21.16)$ & 0.255 \\
\hline Regularity and duration of sleep, $n(\%)$ & $407(31.87)$ & $611(40.41)$ & $<0.001$ \\
\hline \multicolumn{4}{|l|}{ Metabolic syndrome (abnormal values) } \\
\hline High waist circumference, $\mathrm{n}(\%)^{\mathrm{b}}$ & $55(4.38)$ & $50(3.34)$ & 0.155 \\
\hline Low HDL-c levels, n (\%) & $833(65.23)$ & $978(64.68)$ & 0.762 \\
\hline High triglycerides levels, $n$ (\%) & $278(21.77)$ & $497(32.87)$ & $<0.001$ \\
\hline High fasting blood glucose, $n(\%)$ & $67(5.25)$ & $68(4.50)$ & 0.358 \\
\hline High systolic blood pressure, $\mathrm{n}(\%)^{c}$ & $201(16.22)$ & $196(13.17)$ & 0.025 \\
\hline High diastolic blood pressure, $\mathrm{n}(\%)^{c}$ & $130(10.49)$ & $165(11.09)$ & 0.618 \\
\hline \multicolumn{4}{|l|}{ Components metabolic syndrome, $\mathrm{n}(\%)^{d}$} \\
\hline 0 & $280(22.16)$ & $317(21.03)$ & 0.017 \\
\hline 1 & $571(44.87)$ & $615(40.94)$ & \\
\hline 2 & $308(24.12)$ & $419(27.71)$ & \\
\hline 3 & $82(6.42)$ & $132(8.73)$ & \\
\hline 4 & $26(2.04)$ & $19(1.26)$ & \\
\hline 5 & $5(0.39)$ & $5(0.33)$ & \\
\hline
\end{tabular}

Values are means (SD), except for categorical data $\mathrm{n}(\%)$

${ }^{a}$ According to the National Sleep Foundation cut-off [25]; ${ }^{\mathrm{b}}(n=2756)$ (Boys $=1257$ Girls $\left.=1499\right) ;{ }^{c}(n=2727)$ (Boys $=1239$ Girls $\left.=1488\right) ;{ }^{d}$ Three or more components according to Ferranti et al. criteria

increased fasting glucose levels in children and adolescents.

On the other hand, we failed to find significant associations between sleep duration and other MetS components, such as waist circumference, HDL-c, triglycerides, and blood pressure levels, after adjusting for potential confounders, which might be due to selfreported data. Conflicting and sparse data have been 
Table 2 Mean differences of metabolic parameters according sleep duration and sleep quality, by sex

\begin{tabular}{|c|c|c|c|c|c|c|}
\hline \multirow[b]{2}{*}{ Sleep duration } & \multicolumn{3}{|l|}{ Boys } & \multicolumn{3}{|l|}{ Girls } \\
\hline & $\begin{array}{l}\text { Recommended } \\
\text { duration }^{\mathrm{a}}\end{array}$ & $\begin{array}{l}\text { Short-Long } \\
\text { duration }^{\mathrm{a}}\end{array}$ & $P$ value & Recommended duration $^{a}$ & Short-Long duration $^{a}$ & $P$ value \\
\hline Waist circumference, $(\mathrm{cm})$ & $65.91(7.58)$ & $65.04(7.38)$ & 0.545 & $63.77(7.18)$ & $63.12(7.62)$ & 0.393 \\
\hline $\mathrm{HDL}-\mathrm{c}_{,}(\mathrm{mg} / \mathrm{dL})$ & $46.50(12.41)$ & $47.49(12.52)$ & 0.652 & $48.11(12.75)$ & $47.50(11.62)$ & 0.438 \\
\hline Triglycerides, (mg/dL) & $85.78(38.87)$ & $83.70(36.91)$ & 0.463 & $96.03(53.37)$ & $95.31(43.76)$ & 0.722 \\
\hline Fasting blood glucose, (mg/dL) & $84.76(15.79)$ & $83.70(36.91)$ & 0.191 & $82.07(16.16)$ & $82.44(16.20)$ & 0.905 \\
\hline Systolic blood pressure, $(\mathrm{mmHg})$ & $113.72(14.17)$ & $114.00(13.78)$ & 0.427 & $110.70(12.20)$ & $110.89(12.38)$ & 0.801 \\
\hline Diastolic blood pressure, $(\mathrm{mmHg})$ & $68.29(9.60)$ & $68.32(9.34)$ & 0.618 & $68.67(8.81)$ & $68.49(8.94)$ & 0.899 \\
\hline Bedtime problems & Yes & No & $P$ value & Yes & No & $P$ value \\
\hline Waist circumference, $(\mathrm{cm})$ & $65.75(0.45)$ & $65.41(0.48)$ & 0.601 & $63.40(0.41)$ & $63.69(0.32)$ & 0.693 \\
\hline $\mathrm{HDL}-\mathrm{c},(\mathrm{mg} / \mathrm{dL})$ & $45.68(0.89)$ & $46.30(0.97)$ & 0.653 & $47.00(0.87)$ & $48.06(0.69)$ & 0.370 \\
\hline Triglycerides, (mg/dL) & $90.86(2.89)$ & $86.41(3.13)$ & 0.496 & $95.64(3.98)$ & $97.67(3.17)$ & 0.948 \\
\hline Fasting blood glucose, (mg/dL) & $84.97(1.23)$ & $85.93(1.33)$ & 0.602 & $80.12(1.13)$ & $81.47(0.90)$ & 0.463 \\
\hline Systolic blood pressure, $(\mathrm{mmHg})$ & $114.22(1.09)$ & $114.82(1.17)$ & 0.738 & $108.82(0.87)$ & $111.89(0.69)$ & 0.007 \\
\hline Diastolic blood pressure, $(\mathrm{mmHg})$ & $67.44(0.72)$ & $69.70(0.77)$ & 0.030 & $67.50(0.61)$ & $68.91(0.48)$ & 0.088 \\
\hline \multicolumn{7}{|l|}{ Excessive day sleepiness } \\
\hline Waist circumference, $(\mathrm{cm})$ & $65.77(0.55)$ & $65.39(0.36)$ & 0.693 & $63.11(0.35)$ & $63.98(0.38)$ & 0.090 \\
\hline $\mathrm{HDL}-\mathrm{c},(\mathrm{mg} / \mathrm{dL})$ & $46.25(1.10)$ & $45.73(0.73)$ & 0.808 & $48.07(0.76)$ & $46.99(0.81)$ & 0.185 \\
\hline Triglycerides, (mg/dL) & $93.41(3.54)$ & $83.86(2.35)$ & 0.032 & $93.27(3.48)$ & $100.04(3.71)$ & 0.135 \\
\hline Fasting blood glucose, (mg/dL) & $85.81(1.50)$ & $85.09(1.00)$ & 0.575 & $79.98(0.99)$ & $81.62(1.05)$ & 0.208 \\
\hline Systolic blood pressure, (mmHg) & $114.64(1.33)$ & $114.40(0.88)$ & 0.741 & $110.44(0.76)$ & $110.27(0.81)$ & 0.743 \\
\hline Diastolic blood pressure, $(\mathrm{mmHg})$ & $69.28(0.88)$ & $67.87(0.59)$ & 0.153 & $68.12(0.53)$ & $68.28(0.57)$ & 0.821 \\
\hline \multicolumn{7}{|l|}{ Awakenings during the night } \\
\hline Waist circumference, $(\mathrm{cm})$ & $66.05(0.57)$ & $65.10(0.33)$ & 0.185 & $63.46(0.44)$ & $63.63(0.28)$ & 0.615 \\
\hline $\mathrm{HDL}-\mathrm{c},(\mathrm{mg} / \mathrm{dL})$ & $45.20(1.14)$ & $46.77(0.66)$ & 0.129 & $48.26(0.93)$ & $46.80(0.60)$ & 0.175 \\
\hline Triglycerides, (mg/dL) & $90.81(3.68)$ & $86.46(2.14)$ & 0.420 & $98.26(4.26)$ & $95.05(2.77)$ & 0.129 \\
\hline Fasting blood glucose, (mg/dL) & $85.50(1.56)$ & $85.39(0.91)$ & 0.916 & $80.44(1.21)$ & $81.15(0.78)$ & 0.593 \\
\hline Systolic blood pressure, $(\mathrm{mmHg})$ & $115.04(1.38)$ & $114(0.81)$ & 0.509 & $111.20(0.93)$ & $109.51(0.60)$ & 0.199 \\
\hline Diastolic blood pressure, $(\mathrm{mmHg})$ & $69.05(0.91)$ & $68.09(0.53)$ & 0.342 & $68.56(0.65)$ & $67.84(0.42)$ & 0.422 \\
\hline \multicolumn{7}{|l|}{ Regularity and duration of sleep } \\
\hline Waist circumference, $(\mathrm{cm})$ & $64.97(0.51)$ & $66.19(0.42)$ & 0.127 & $63.58(0.33)$ & $63.51(0.40)$ & 0.953 \\
\hline $\mathrm{HDL}-\mathrm{c},(\mathrm{mg} / \mathrm{dL})$ & $46.05(1.02)$ & $45.93(0.83)$ & 0.791 & $47.06(0.70)$ & $48.00(0.85)$ & 0.369 \\
\hline Triglycerides, (mg/dL) & $87.21(3.29)$ & $90.06(2.70)$ & 0.631 & $97.90(3.23)$ & $95.40(3.92)$ & 0.557 \\
\hline Fasting blood glucose, (mg/dL) & $85.66(1.40)$ & $85.23(1.15)$ & 0.828 & $81.91(0.92)$ & $79.69(1.11)$ & 0.126 \\
\hline Systolic blood pressure, $(\mathrm{mmHg})$ & $114.48(1.23)$ & $114.56(1.02)$ & 0.987 & $111.00(0.70)$ & $109.71(0.86)$ & 0.244 \\
\hline Diastolic blood pressure, $(\mathrm{mmHg})$ & $68.59(0.81)$ & $68.56(0.67)$ & 0.932 & $68.45(0.49)$ & $67.96(0.60)$ & 0.563 \\
\hline
\end{tabular}

Data are means (SD). Analysis adjusted by age, sexual maturity, body mass index (except for waist circumference), and cardiorespiratory fitness. ${ }^{\text {a }}$ According to the National Sleep Foundation cut-off [25]

encountered on the impact of sleep time on these components of MetS in children and adolescents [10, 12, 13, 35]. The discrepancies identified across different studies could be explained in part by the following reasons. Remarkably, most studies investigating these associations have been conducted in overweight and obese children and adolescents [7, 13, 16, 35]. Note that our study population included underweight, normal-weight, overweight, and obese subjects. Furthermore, in this study, considering the recommendations of the National Sleep Foundation, $9 \mathrm{~h}$ per night was taken as the ideal cut-off point; however, not all studies above-mentioned have used the same cut-off point.

On the other hand, we found that $39.5 \%$ of children and adolescents obtained short or long duration of sleep on a regular basis. Likewise, data from the 2016 United 
Table 3 Odd ratios of metabolic parameters from sleep duration and sleep patterns, by sex

\begin{tabular}{|c|c|c|c|c|c|c|}
\hline & \multicolumn{3}{|l|}{ Boys } & \multicolumn{3}{|l|}{ Girls } \\
\hline & $\mathrm{OR}$ & $(95 \% \mathrm{Cl})$ & $P$ value & $\mathrm{OR}$ & $(95 \% \mathrm{Cl})$ & $P$ value \\
\hline \multicolumn{7}{|l|}{ Sleep Duration } \\
\hline High waist circumference & 1.79 & $(0.77-4.18)$ & 0.175 & 1.54 & $(0.76-3.12)$ & 0.226 \\
\hline Low HDL & 1.05 & $(0.80-1.39)$ & 0.701 & 1.07 & $(0.84-1.36)$ & 0.569 \\
\hline High triglycerides & 0.93 & $(0.68-1.26)$ & 0.634 & 1.03 & $(0.80-1.32)$ & 0.815 \\
\hline High fasting blood glucose & 0.71 & $(0.40-0.94)$ & 0.031 & 1.26 & $(0.74-2.12)$ & 0.392 \\
\hline High systolic blood pressure & 1.12 & $(0.81-1.56)$ & 0.482 & 1.09 & $(0.78-1.53)$ & 0.607 \\
\hline High diastolic blood pressure & 0.77 & $(0.51-1.16)$ & 0.221 & 0.76 & $(0.54-1.09)$ & 0.145 \\
\hline Presence metabolic syndrome & 0.86 & $(0.54-1.36)$ & 0.513 & 0.77 & $(0.53-1.13)$ & 0.181 \\
\hline \multicolumn{7}{|l|}{ Bedtime problems } \\
\hline High waist circumference & 0.62 & $(0.19-2.01)$ & 0.433 & 0.53 & $(0.24-1.32)$ & 0.175 \\
\hline Low HDL & 0.92 & $(0.65-1.30)$ & 0.655 & 1.08 & $(0.80-1.44)$ & 0.600 \\
\hline High triglycerides & 1.29 & $(0.94-1.76)$ & 0.112 & 1.00 & $(0.74-1.34)$ & 0.987 \\
\hline High fasting blood glucose & 0.76 & $(0.40-1.46)$ & 0.424 & 1.51 & $(0.73-3.08)$ & 0.259 \\
\hline High systolic blood pressure & 1.07 & $(0.70-1.65)$ & 0.732 & 1.11 & $(0.73-1.69)$ & 0.608 \\
\hline High diastolic blood pressure & 0.78 & $(0.48-1.26)$ & 0.316 & 1.17 & $(0.75-1.82)$ & 0.477 \\
\hline Presence metabolic syndrome & 0.72 & $(0.42-1.25)$ & 0.253 & 1.46 & $(0.89-2.39)$ & 0.129 \\
\hline \multicolumn{7}{|l|}{ Excessive day sleepiness } \\
\hline High waist circumference & 1.04 & $(0.39-2.79)$ & 0.926 & 0.88 & $(0.43-1.76)$ & 0.719 \\
\hline Low HDL & 1.36 & $(1.02-1.83)$ & 0.036 & 0.99 & $(0.78-1.26)$ & 0.977 \\
\hline High triglycerides & 0.88 & $(0.64-1.23)$ & 0.482 & 1.28 & $(1.01-1.63)$ & 0.045 \\
\hline High fasting blood glucose & 1.15 & $(0.63-2.10)$ & 0.645 & 0.96 & $(0.55-1.65)$ & 0.882 \\
\hline High systolic blood pressure & 1.21 & $(0.83-1.77)$ & 0.317 & 1.27 & $(0.90-1.80)$ & 0.172 \\
\hline High diastolic blood pressure & 1.00 & $(0.65-1.54)$ & 0.979 & 1.24 & $(0.87-1.78)$ & 0.229 \\
\hline Presence metabolic syndrome & 1.46 & $(0.86-2.47)$ & 0.151 & 1.24 & $(0.84-1.82)$ & 0.262 \\
\hline \multicolumn{7}{|l|}{ Awakenings during the night } \\
\hline High waist circumference & 0.82 & $(0.27-2.49)$ & 0.732 & 1.81 & $(0.80-4.09)$ & 0.149 \\
\hline Low HDL & 1.01 & $(0.70-1.44)$ & 0.954 & 1.27 & $(0.94-1.72)$ & 0.115 \\
\hline High triglycerides & 1.10 & $(0.73-1.66)$ & 0.631 & 1.00 & $(0.74-1.36)$ & 0.966 \\
\hline High fasting blood glucose & 1.89 & $(0.84-4.20)$ & 0.119 & 0.77 & $(0.39-1.52)$ & 0.465 \\
\hline High systolic blood pressure & 0.85 & $(0.55-1.32)$ & 0.495 & 0.70 & $(0.46-1.07)$ & 0.105 \\
\hline High diastolic blood pressure & 0.83 & $(0.50-1.38)$ & 0.491 & 0.97 & $(0.62-1.52)$ & 0.902 \\
\hline Presence metabolic syndrome & 1.34 & $(0.73-2.48)$ & 0.337 & 0.97 & $(0.60-1.59)$ & 0.927 \\
\hline \multicolumn{7}{|l|}{ Regularity and duration of sleep } \\
\hline High waist circumference & 0.47 & $(0.19-1.18)$ & 0.111 & 0.55 & $(0.25-1.18)$ & 0.126 \\
\hline Low HDL & 0.96 & $(0.71-1.29)$ & 0.820 & 0.71 & $(0.55-0.91)$ & 0.009 \\
\hline High triglycerides & 0.97 & $(0.69-1.35)$ & 0.864 & 0.98 & $(0.76-1.26)$ & 0.891 \\
\hline High fasting blood glucose & 0.65 & $(0.37-1.14)$ & 0.135 & 1.01 & $(0.57-1.78)$ & 0.972 \\
\hline High systolic blood pressure & 0.98 & $(0.68-1.41)$ & 0.919 & 1.05 & $(0.73-1.51)$ & 0.766 \\
\hline High diastolic blood pressure & 0.89 & $(0.58-1.36)$ & 0.603 & 0.86 & $(0.60-1.25)$ & 0.457 \\
\hline Presence metabolic syndrome & 0.87 & $(0.54-1.41)$ & 0.579 & 1.07 & $(0.72-1.59)$ & 0.719 \\
\hline
\end{tabular}

Reference group (Odds Ratio = 1.0): short-long duration sleep duration or non-sleep problem. Analysis adjusted by age, sexual maturity, body mass index (except for waist circumference), and cardiorespiratory fitness 
States Youth Risk Behavior Survey reported that the prevalence of obtaining 8 or more hours of sleep was $27.3 \%$ [36]. Moreover, in line with a previous published study [37], excessive daytime sleepiness and lack of regular sleep were the most prevalent sleep problems in the Latin American pediatric population $(44.51 \%$ and $40.41 \%$, respectively). In addition, we observed that girls slept less than boys and presented a higher prevalence of sleep problems (assessed with the Pittsburgh Sleep Quality Index); similar results were found in a cohort of Brazilian overweight or obese children and adolescents (aged 5-18 years) [16].

Because sleep is a multidimensional construct, in addition to sleep duration, it was especially relevant to identify whether sleep quality was associated with metabolic risk factors. To date, evidence regarding the effect of sleep quality on metabolic risk is lacking, because the majority of studies conducted in the pediatric population have focused on sleep duration $[14,15]$. We found that excessive sleepiness during the day was related to lower levels of HDL-c in boys (OR $=1.36,95 \% \mathrm{CI}$ [1.02-1.83], $p=0.036$ ), and higher levels of triglycerides in girls $(\mathrm{OR}=1.28,95 \% \mathrm{CI}[1.01-1.63], p=0.045)$. In agreement with our findings, Berentzen et al. (2016) reported that in a cohort of 1481 children, subjects who felt sleepy during the day also had lower HDL-c levels [14]. Similarly, a longitudinal study showed that poor sleep quality was linked to higher triglyceride levels [14]. Interestingly, in our study, irregular sleep patterns were linked to a protective HDL-c levels in girls $(\mathrm{OR}=0.71,95 \% \mathrm{CI}[0.55-0.91]$, $p=0.009$ ). Taken together, these lines of evidence indicate that sleep patterns may have an importance influence on serum lipids levels. However, due to the limited evidence regarding sleep quality and components of the MetS, further research is needed to confirm our preliminary results.

The present study indicates that sleep duration and sleep-related problems are not associated with MetS. Previous data in different cohorts of children and adolescents have showed conflicting findings, mostly negative $[1,12-$ 14, 16, 38]. Note that in data from 1187 adolescents of the Korean National Health and Nutrition Examination Survey (KNHANES) IV, although there were relationships between sleep duration and MetS components, no association was identified with the MetS [12]. The contrasting relationships observed in our study may be explained by a lack of statistical power due to the low prevalence of MetS (9.65\%).

There are some limitations to the present study. Firstly, the cross-sectional design does not allow us to make cause effect inferences between sleep duration and MetS components. Thus, additional prospectively and intervention are necessary to determine causal links. Secondly, because sleep measurements were based on the self-report method instead of objective polysomnography or accelerometry, limitations in terms of reliability and validity are inherent in the methodology. Nevertheless, objective measures of sleep are often not suitable for large epidemiologic studies due to its high costs. Moreover, a rather high correlation between subjective and objective sleep indices in children has been identified [39]. Also, youths were asked to express the data on sleep as the mean of more days, which could influence on the reliability of the data.

Similarly, there are several confounders that may influence and modulate the association between sleepdisordered breathing and MetS. Variables such as physical activity, diet, socioeconomic status, menstrual cycle and race are likely important modulators of this association. On the other hand, snoring as another important risk factors for developing MetS at early ages. In this context, in the present study, this item was not assessed because sleep-related problems were self-reported by participants. However, the extent to which each of metabolic abnormalities factors interact with snoring and contributes to the development of metabolic consequences in snoring youth population has yet to be delineated [40]. Finally, it is important to highlight that the BEARS questionnaire has been postulated as a useful pediatric sleep screening tool for identifying sleep problems [27] and recently a previous article supports the concurrent and reliability validity of the Spanish translation of the BEARS to detect sleep problems in pediatric nursing assessments $[28,41]$.

On the other hand, the main strength of this study is the large representative sample that allowed us to provide data on a national scale. Furthermore, highly standardized procedures were developed within the FRUPECOL study to avoid measurement bias. Moreover, information on age, sexual maturity, and cardiorespiratory fitness were considered as potential confounding variables.

\section{Conclusion}

To the best of our knowledge, this is the first study to describe comprehensively the relationship between sleep duration and sleep related-problems and metabolic markers in Latin American children and adolescents. We report novel results on the relationship between sleep characteristics and elements of the MetS. Our study found that recommended sleep duration based on subjective parameters was associated with decreased fasting glucose levels, and poor sleep quality was related to lower HDL-c and higher triglyceride levels, suggesting the clinical importance of improving sleep hygiene to reduce metabolic risk factors in children and adolescents. In contrast, we could not find significant relationship in the rest of the parameters, which might be due to self-reported data. Future prospective and intervention studies with objective assessments are needed to establish a possible causal link between sleep patterns and metabolic risk factors. 


\section{Abbreviations}

BMl: Body mass index; DBP: Diastolic blood pressure; HDL-c: High-density lipoprotein cholesterol; LDL-c: Low high-density lipoprotein cholesterol; MetS: Metabolic syndrome; OR: Odds Ratio; SBP: Systolic blood; WC: Waist circumference

\section{Acknowledgments}

The we thank all participants, parents, and elementary schools that participated in this investigation.

\section{Funding}

The FUPRECOL Study was possible due to the financial support provided by the Instituto Colombiano para el Desarrollo de la Ciencia y la Tecnología "Francisco José de Caldas" COLCIENCIAS (Contract N 671-2014 Code 122265743978). The funder had no role in the study design, data collection, data analysis and interpretation, preparation of the manuscript, or decision to publish

\section{Availability of data and materials}

The study data have legal restrictions and ethical imposed by the authors' IRB (Universidad del Rosario). The explanation of these restrictions is because they are children and adolescent students of Public Schools Colombia (Law $N^{\circ}$ 1.581, October 2012 and National Law N 1377 de 2013). From: http:// www.alcaldiabogota.gov.co/sisjur/normas/Norma1.jsp?i=49981 and http:// www.oei.es/quipu/colombia/codigo_infancia.pdf Contact for the raw data. The initial contact point for collaborations is Professor Robinson Ramirez-Velez (robinson.ramirez@urosario.edu.co).

\section{Authors' contributions}

RR-V, LP-A, AG-H and JEC-B conceived, designed the study and analyzed the data; CA-S, JM, RS, and MC-R analyzed the data and wrote the paper. All authors read and approved the final manuscript

\section{Ethics approval and consent to participate}

The protocol was in accordance with the latest revision of the Declaration of Helsinki and current Colombian laws governing clinical research on human subjects (Resolution 008430/1993 Ministry of health). The Review Committee for Research on Human Subjects at the University of Rosario [Code $N^{\circ}$ CElABN026-000262] approved all of the study procedures. Informed consent and assent were obtained from all participants.

\section{Consent for publication}

I have obtained consent to publish from the participants (or legal parents or guardians for children) to report individual patient data.

\section{Competing interests}

The authors declare that they have no competing interests.

\section{Publisher's Note}

Springer Nature remains neutral with regard to jurisdictional claims in published maps and institutional affiliations.

\section{Author details}

${ }^{1}$ Center of Studies in Physical Activity Measurements, School of Medicine and Health Sciences, Universidad del Rosario, Bogotá D.C, Colombia. ${ }^{2}$ Research Center in Physical Activity, Health, and Leisure, Faculty of Sport, University of Porto, Porto, Portugal. ${ }^{3}$ Early Start Research Institute, Faculty of Social Sciences, School of Education, University of Wollongong, Wollongong, Australia. ${ }^{4}$ Faculty of Health Sciences, University of Granada, Granada, Spain. ${ }^{5}$ Physical Activity, Sport and Health Sciences Laboratory, Faculty of Medical Sciences, Universidad de Santiago de Chile, USACH, Santiago, Chile.

\section{Received: 1 November 2017 Accepted: 8 January 2018}

\section{Published online: 15 January 2018}

\section{References}

1. Knutson KL. Sleep duration and cardiometabolic risk: a review of the epidemiologic evidence. Best Pr Res Clin Endocrinol Metab. 2010;24:731-43. https://doi.org/10.1016/j.beem.2010.07.001.Sleep.

2. Beccuti G, Pannain S. Sleep and obesity. Curr Opin Clin Nutr Metab Care 2011;14:402-12. https://doi.org/10.1097/MCO.0b013e3283479109.
3. Gangwisch JE, Heymsfield SB, Boden-Albala B, et al. Sleep duration as a risk factor for diabetes incidence in a large U.S. sample. Sleep. 2007;30:1667-73.

4. Javaheri S, Storfer-Isser A, Rosen CL, Redline S. Sleep quality and elevated blood pressure in adolescents. Circulation. 2008;118:1034-40. https://doi. org/10.1161/CIRCULATIONAHA.108.766410.

5. Gozal D, Dumin M, Koren D. Role of sleep quality in the metabolic syndrome. Diab Metab Syndr Obes Targets Ther Volume. 2016;9:281-310. https://doi.org/10.2147/DMSO.S95120.

6. Tian Z, Ye T, Zhang $X$, et al. Sleep duration and hyperglycemia among obese and nonobese children aged 3 to 6 years. Arch Pediatr Adolesc Med. 2010;164:46-52. https://doi.org/10.1001/archpediatrics.2009.233.

7. Koren D, Katz LEL, Brar PC, et al. Sleep architecture and glucose and insulin homeostasis in obese adolescents. Diabetes Care. 2011;34:2442-7. https:// doi.org/10.2337/dc11-1093.

8. Zhu Y, Li AM, Au CT, et al. Association between sleep architecture and glucose tolerance in children and adolescents. J Diabetes. 2015;7:10-5. https://doi.org/10.1111/1753-0407.12138.

9. Javaheri S, Storfer-Isser A, Rosen CL, Redline S. Association of Short and Long Sleep Durations with insulin sensitivity in adolescents. J Pediatr. 2011; 158:617-23. https://doi.org/10.1016/j.jpeds.2010.09.080.

10. Azadbakht L, Kelishadi R, Khodarahmi M, et al. The association of sleep duration and cardiometabolic risk factors in a national sample of children and adolescents: the CASPIAN III study. Nutrition. 2013;29:1133-41. https:// doi.org/10.1016/j.nut.2013.03.006

11. Iglayreger HB, Peterson MD, Liu D, et al. Sleep duration predicts cardiometabolic risk in obese adolescents. J Pediatr. 2014;164:1085-1090.e1. https://doi.org/10.1016/j.jpeds.2014.01.034.

12. Lee JA, Park HS. Relation between sleep duration, overweight, and metabolic syndrome inKorean adolescents. Nutr Metab Cardiovasc Dis. 2014;24:65-71. https://doi.org/10.1016/j.numecd.2013.06.004.

13. Sung $V$, Beebe DW, Vandyke $R$, et al. Does sleep duration predict metabolic risk in obese adolescents attending tertiary services? A cross-sectional study. Sleep. 2011;34:891-8. https://doi.org/10.5665/SLEEP.1122.

14. Kuula L, Pesonen A-K, Kajantie E, et al. Sleep and lipid profile during transition from childhood to adolescence. J Pediatr. 2016;177:173-178.e1. https://doi.org/10.1016/j.jpeds.2016.06.026.

15. Berentzen NE, Smit HA, Bekkers MBM, et al. Time in bed, sleep quality and associations with cardiometabolic markers in children: the prevention and incidence of asthma and mite allergy birth cohort study. J Sleep Res. 2014; 23:3-12. https://doi.org/10.1111/jsr.12087.

16. Gonzaga NC, Sena ASS, Coura AS, et al. Sleep quality and metabolic syndrome in overweight or obese children and adolescents. Rev Nutr. 2016; 29:377-89. https://doi.org/10.1590/1678-98652016000300008

17. Ramírez-Vélez R, García-Hermoso A, Agostinis-Sobrinho C, et al. Pubertal stage, body mass index, and Cardiometabolic risk in children and adolescents in Bogotá, Colombia: the cross-sectional Fuprecol study. Nutrients. 2017;9:644. https://doi.org/10.3390/nu9070644.

18. de Onis M, Onyango AW, Borghi E, et al. Development of a WHO growth reference for school-aged children and adolescents. Bull World Health Organ. 2007;85:660-7. https://doi.org/10.2471/BLT.07.043497.

19. Marfell-Jones M, Olds T, Stewart A. International Society for the Advancement of Kinanthropometry. International standards for anthropometric assessment. South Africa ISAK: Potchefstroom; 2001.

20. de Ferranti SD, Gauvreau K, Ludwig DS, et al. Prevalence of the metabolic syndrome in American adolescents: findings from the third National Health and nutrition examination survey. Circulation. 2004;110:2494-7. https://doi. org/10.1161/01.CIR.0000145117.40114.C7.

21. Magge SN, Goodman E, Armstrong SC, et al. The metabolic syndrome in children and adolescents: shifting the focus to Cardiometabolic risk factor clustering. Pediatrics. 2017;140:e20171603. https://doi.org/10.1542/peds. 2017-1603.

22. Léger LA, Mercier D, Gadoury C, Lambert J. The multistage 20 metre shuttle run test for aerobic fitness. J Sports Sci. 1988;6:93-101. https://doi.org/10. 1080/02640418808729800.

23. Ramírez-Vélez R, Palacios-López A, Humberto Prieto-Benavides D, et al. Normative reference values for the 20 m shuttle-run test in a populationbased sample of school-aged youth in Bogota, Colombia: the FUPRECOL study. Am J Hum Biol. 2016; https://doi.org/10.1002/ajhb.22902.

24. García-Hermoso A, Aguilar MM, Vergara FA, Velásquez EJ, Marina R. Obesity, Cardiorespiratory fitness, and self-reported sleep patterns in Chilean schoolaged children. Behav Sleep Med. 2007;15:70-80 
25. Tanner JM, Whitehouse RH. Clinical longitudinal standards for height, weight, height velocity, weight velocity, and stages of puberty. Arch Dis Child. 1976;51:170-9.

26. Hirshkowitz M, Whiton K, Albert SM, et al. National Sleep Foundation's sleep time duration recommendations: methodology and results summary. Sleep Heal. 2015;1:40-3. https://doi.org/10.1016/j.sleh.2014.12.010.

27. Owens JA, Dalzell V. Use of the "BEARS" sleep screening tool in a pediatric residents' continuity clinic: a pilot study. Sleep Med. 2005;6:63-9. https://doi. org/10.1016/j.sleep.2004.07.015.

28. Bastida-Pozuelo MF, Sánchez-Ortuño MM. Preliminary analysis of the concurrent validity of the Spanish translation of the BEARS sleep screening tool for children. J Psychiatr Ment Health Nurs. 2016;23:513-20. https://doi. org/10.1111/jpm.12338.

29. Matthews KA, Pantesco EJM. Sleep characteristics and cardiovascular risk in children and adolescents: an enumerative review. Sleep Med. 2016; https:// doi.org/10.1016/.jsleep.2015.06.004.

30. Koren D, O'Sullivan KL, Mokhlesi B. Metabolic and Glycemic Sequelae of sleep disturbances in children and adults. Curr Diab Rep. 2015;15:562. https://doi.org/10.1007/s11892-014-0562-5.

31. Felső R, Lohner $\mathrm{S}$, Hollódy K, Erhardt É, Molnár D. Relationship between sleep duration and childhood obesity: systematic review including the potential underlying mechanisms. Nutr Metab Cardiovasc Dis. 2017:27: 751-61.

32. Sayin FK, Buyukinan M. Sleep duration and media time have a major impact on insulin resistance and metabolic risk factors in obese children and adolescents. Child Obes. 2016;12:272-8. https://doi.org/10. 1089/chi.2015.0126.

33. Leproult R, Deliens G, Gilson M, et al. Beneficial Impact of Sleep Extension on Fasting Insulin Sensitivity in Adults with Habitual Sleep Restriction. Sleep. 2015;38:707-15. https://doi.org/10.5665/sleep.4660

34. Killick R, Hoyos CM, Melehan KL, et al. Metabolic and hormonal effects of "catch-up" sleep in men with chronic, repetitive, lifestyle-driven sleep restriction. Clin Endocrinol. 2015;83:498-507. https://doi.org/10. 1111/cen.12747.

35. Quist JS, Sjödin A, Chaput JP, et al. Sleep and cardiometabolic risk in children and adolescents. Sleep Med Rev. 2016;29:76-100. https://doi.org/10. 1016/.j.smrv.2015.09.001.

36. Kann L, McManus T, Harris WA, et al. Youth risk behavior surveillance -United States, 2015. MMWR Surveill Summ. 2016;65:1-174. https://doi.org/ 10.15585/mmwr.ss6506a1.

37. Ebarhim A, Babak G, Alimohammad A, et al. High prevalence of sleep problems in school- and preschool-aged children in Tehran: a population based study. Iran J Pediatr. 2013;23:45-52.

38. Rey-López JP, de Carvalho HB, de Moraes ACF, et al. Sleep time and cardiovascular risk factors in adolescents: the HELENA (healthy lifestyle in Europe by nutrition in adolescence) study. Sleep Med. 2014;15:104-10. https://doi.org/10.1016/j.sleep.2013.07.021.

39. Gaina A, Sekine M, Chen $X$, et al. Validity of child sleep diary questionnaire among junior high school children. J Epidemiol. 2004;14:1-4.

40. Brockmann PE, Damiani F, Smith DL, et al. Metabolic consequences of snoring in adolescents and younger adults: a population study in Chile. Int J Obes. 2016;40:1510-4.

41. Ramírez-Vélez R, Huertas-Zamora L, Correa-Bautista JE, Cárdenas-Calderón EG. Confiabilidad y validez del cuestionario de trastornos de sueño BEARS en niños y adolescentes escolares de Bogotá, D.C., Colombia: Estudio FUPRECOL. Retos. 2018;34:89-93.

\section{Submit your next manuscript to BioMed Central and we will help you at every step:}

- We accept pre-submission inquiries

- Our selector tool helps you to find the most relevant journal

- We provide round the clock customer support

- Convenient online submission

- Thorough peer review

- Inclusion in PubMed and all major indexing services

- Maximum visibility for your research

Submit your manuscript at www.biomedcentral.com/submit 